\title{
Breakerless Protection for Voltage Source Converter-Based Marine DC Power Supply Systems
}

S. Kim, D. Lee, S.-N. Kim, et al.

This material is posted here with permission of the IEEE. Such permission of the IEEE does not in any way imply IEEE endorsement of any of EPFL's products or services. Internal or personal use of this material is permitted. However, permission to reprint / republish this material for advertising or promotional purposes or for creating new collective works for resale or redistribution must be obtained from the IEEE by writing to pubs-permissions@ieee. org. By choosing to view this document, you agree to all provisions of the copyright laws protecting it. 


\section{Breakerless Protection for Voltage Source Converter-Based Marine DC Power Supply Systems}

\author{
Seongil Kim*, Ducksoo Lee, Soo-Nam Kim \\ Future Power Grid Research Department \\ Hyundai Electric \& Energy Systems Research Centre \\ Yongin, Republic of Korea \\ *kim.seongil@hyundai-electric.com
}

\author{
Drazen Dujic \\ Power Electronics Laboratory (PEL) \\ École Polytechnique Fédérale de Lausanne (EPFL) \\ Lausanne, Switzerland \\ drazen.dujic@epfl.ch
}

\begin{abstract}
DC power supply systems utilising voltage source converters offer several advantages compared with their counterparts in marine low-voltage DC power distribution networks. In case of a two-level voltage source converter fed by a synchronous generator which is widely employed, a solid-state circuit breaker or a high-speed fuse is necessary for the converter protection due to its no fault-handling function and low fault withstand capability. However, the use of the solid-state circuit breaker and the high-speed fuse makes such a DC solution expensive and less reliable, respectively. Hence, this paper proposes a breakerless protection method for the voltage source converter-based marine DC power supply systems. The proposed method consists of an artificial short circuit on $\mathrm{AC}$ side (between the generator and the converter) and generator deexcitation. By employing the proposed method, the fault energy passing through the converter can be mitigated by the artificially generated short circuit between them and the current from the generator finally becomes zero by the deexcitation. This method allows for managing the fault energy under the converter and generator withstand capabilities without relying on the conventional breaking devices.
\end{abstract}

Index Terms-artificial short circuit, breakerless protection, DC power supply systems, generator deexcitation, VSC

\section{INTRODUCTION}

At present there are three-dominant power supply systems for commercial marine low-voltage DC (LVDC) power distribution networks (system voltage of around $1 \mathrm{kV}$ and power rating up to $20 \mathrm{MW}$ ): a six-pulse diode rectifier, a six-pulse thyristor rectifier, and a two-level voltage source converter (VSC), as presented in Table I. They can be fed by a synchronous generator (SG), whereas the VSC can also be coupled with a permanent magnet synchronous generator (PMSG).

On one hand, for such a voltage level, the two-level VSC is generally composed of insulated-gate bipolar transistor (IGBT) modules (an IGBT with an anti-parallel diode in the module). Unlike the VSC, the others are typically assembled with press pack devices. As the fault withstand capability of the IGBT module is lower than that of the press pack devices, faster protection is required for the VSC protection. On the other hand, the two-level IGBT-based VSC has no function to control the fault current through the converter. Albeit the VSC stops the IGBTs switching after fault detection, the fault
TABLE I: LVDC solutions for marine applications [1].

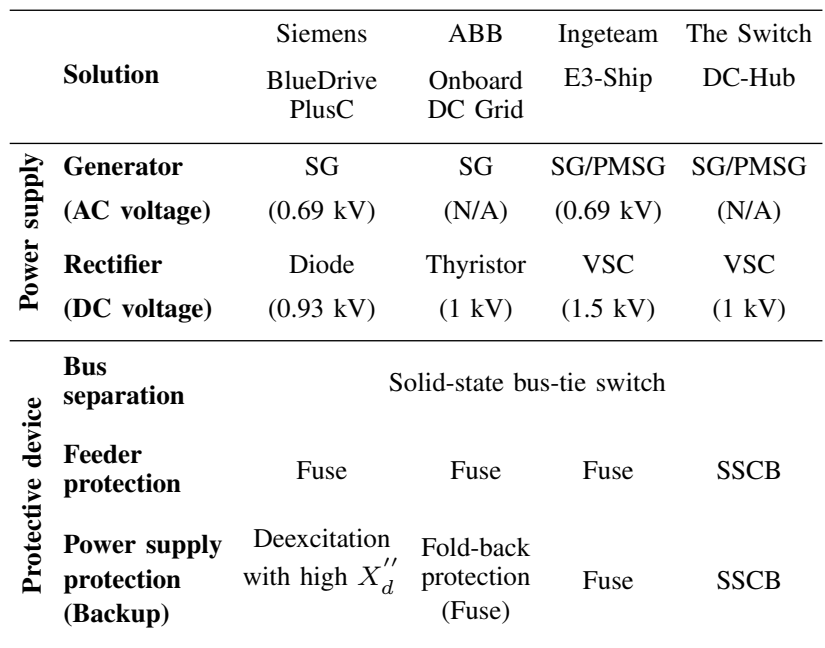

current still flows through the anti-parallel diodes, acting as a six-pulse diode rectifier.

Those are the main reasons why an ultra-fast solid-state circuit breaker (SSCB) or a high-speed fuse has been employed for the VSC-based DC power supply systems [2], [3]. However, the SSCB is not yet readily available on the market and its expected cost may make the VSC-based DC solution less competitive. Furthermore, the use of the highspeed fuse for the power supply protection has an exceptional disadvantage in protection reliability due to its high tolerance and passive way of interrupting the current.

To achieve the VSC protection without relying on the SSCB or the DC fuse, an artificial short circuit (ASC) combined with an $\mathrm{AC}$ circuit breaker, all mature $\mathrm{AC}$ technologies, was proposed by [4] as the circuit breaker alone is too slow to avoid the failure of the module. The main limitation of this work is that the method still requires the installation of the circuit breaker and the protective relay.

The key technology of the diode rectifier protection is the deexcitation of the synchronous generator having high subtransient reactance (see Table I) [5]. The fault current amplitude and energy are controlled within the ratings of a diode rectifier by the high subtransient reactance and the 
deexcitation, respectively. However, the long duration of the fault current by the deexcitation makes it inappropriate to the VSC protection. By taking the advantages of the above two methods, this paper proposes an innovative breakerless protection method based on the ASC method, mitigating the through fault current of the VSC, and the generator deexcitation, eliminating the fault current generation without relying on the AC circuit breaker.

\section{Proposed Breakerless Protection Method}

The working principle of the ASC method is presented with technical discussions on an ASC device and a short-circuit resistor $\left(R_{A S C}\right)$ intentionally inserted to adjust the fault level, followed by the fault current elimination by the generator deexcitation.

\section{A. ASC Method}

When a DC short-circuit fault occurs, the overcurrent protection of the VSC blocks the operation of the IGBTs by removing gate signals and then the circuit becomes the same as the six-pulse diode rectifier (see Fig. 1). The anti-parallel diodes in the converter experience the fault current during this period (green-colored dot lines in Fig. 1). The artificial three-phase short circuit on the AC side enables to mitigate the fault current passing through the anti-parallel diodes by providing a low-impedance current path (orange-colored dot lines in Fig. 1). The ASC can be generated within $4 \mathrm{~ms}$ after the fault detection, considering commercially available fast earthing switches [6], [7].

If the ASC current is too high, it is a severe fault in the vicinity of the machine and may cause machine damage. Furthermore, the making of the ASC device is impossible if the overcurrent is higher than the device rating. Hence, the overcurrent level should be managed to be lower than the making capability of the short-circuit device $\left(I_{c m}=50 \mathrm{kA}_{\text {peak }}\right.$ in this study [6]). The short-circuit resistance $\left(R_{A S C}\right)$ which is not considered in the previous work of [4] is newly employed to adjust the overcurrent level below the device rating.

The initial amplitude of the ASC current is decided by all impedances along the paths, i.e., the direct axis subtransient reactance $\left(X_{d}^{\prime \prime}\right)$, the AC cable impedances $\left(R_{\text {cable }}\right.$ and $\left.X_{\text {cable }}\right)$,

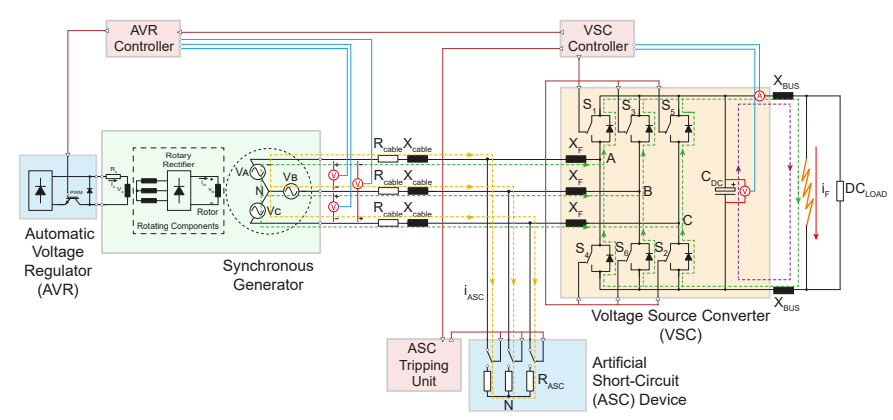

Fig. 1: Schematic diagram of the proposed breakerless protection method. the AC reactor $\left(X_{F}\right)$, the short-circuit resistance $\left(R_{A S C}\right)$, the DC busbar reactance $\left(X_{B U S}\right)$, and the DC fault resistance $\left(R_{f}\right)$. For the reliable making of the ASC device, the shortcircuit resistor should be chosen to limit the maximum making current at the instant of closing $\left(i_{A S C}\right)$ below the maximum conducting current of the ASC device $\left(I_{c m}\right)$ as

$$
I_{c m} \geq i_{A S C}=\frac{\sqrt{2} V_{a c}}{2 Z_{S}^{\prime \prime}+2 Z_{A S C} / / 2 Z_{D C}} \frac{Z_{D C}}{Z_{A S C}+Z_{D C}}
$$

where

$$
\begin{aligned}
V_{a c} & =V_{s a}-V_{s c}, \\
Z_{A S C} & =R_{A S C}, \\
Z_{S}^{\prime \prime} & =\sqrt{\left(R_{a}+R_{c a b l e}\right)^{2}+\left(X_{d}^{\prime \prime}+X_{c a b l e}\right)^{2}}, \text { and } \\
Z_{D C} & =\sqrt{\left(R_{f} / 2\right)^{2}+\left(X_{F}+X_{B U S}\right)^{2}} .
\end{aligned}
$$

The management of the fault energy passing through the IGBT module is discussed in the following subsection.

\section{B. Generator Deexcitation}

The generator deexcitation (the demagnetization of the synchronous generator) can diminish the fault current supplied from the generator in time and finally makes the current zero. Due to the way to limit the fault current, the current under the deexcitation is the function of the exciter and transient time constants and it takes a relatively long duration to completely eliminate it [4], [8].

The initial fault current from the generator flows through the VSC for the DC fault as

$$
i_{F}(0)=\frac{\sqrt{2} V_{a c}}{2 Z_{S}^{\prime \prime}+2 Z_{A S C} / / 2 Z_{D C}}
$$

Once the VSC controller detects the fault, it sends a signal to the ASC tripping unit and thus the ASC is generated at $t_{A S C}(4 \mathrm{~ms}$ in this study). This provides the branch circuit to mitigate the through fault current of the VSC as

$$
i_{F}\left(t_{A S C}\right)=\frac{\sqrt{2} V_{a c}}{2 Z_{S}^{\prime \prime}+2 Z_{A S C} / / 2 Z_{D C}} \frac{Z_{A S C}}{Z_{A S C}+Z_{D C}}
$$

Comprehensive studies on the generator deexcitation is conducted by [8]. The work of [8] provides the fault current change by the deexcitation, also considering the generator dynamics as

$$
i_{F}(t)=\sqrt{2} V_{a c} Y(t) F(t)
$$

where the contribution of the DC link capacitor and the unidirectional transient component [9] are not considered. $Y(t)$ is the equivalent impedance varied by the three distinctive generator dynamics (subtransient, transient, and steady-state) and $F(t)$ is the change in the fault current limited by the deexcitation. Full equations of $Y(t)$ and $F(t)$ are provided in Appendix. 
By combining (2), (3), and (4), the through fault current by the proposed method is

$$
\begin{aligned}
i_{F}(t)= & \sqrt{2} V_{a c} Y(t) F(t) \times \\
& \left(1-u\left(t-t_{A S C}\right)+u\left(t-t_{A S C}\right) \frac{Z_{A S C}}{Z_{A S C}+Z_{D C}}\right)
\end{aligned}
$$

As the two-level VSC acts as the six-pulse diode rectifier after the fault detection, each anti-parallel diode experiences the fault current with the one-third phase interval. Thus, the limiting load integral of the diode $\left(I^{2} t_{D}\right)$ shoud be higher than the maximum through current energy as

$$
I^{2} t_{D} \geq \frac{1}{3} \int_{0}^{\infty} i_{F}^{2}(t) \mathrm{d} t
$$

The important thing in this method is to coordinate between the peak ASC current and the converter through fault energy by selecting properly the short-circuit resistance $\left(R_{A S C}\right)$.

\section{Modeling OF DC POWER Supply Systems}

This section describes the modeling of the VSC-based DC power supply systems which consist of a synchronous generator with a brushless exciter driven by a diesel engine, a VSC, AC cables, AC and DC filters, DC busbars, a fault impedance, and two induction machines driven by voltage source inverters (VSI), as shown in Fig. 2.

\section{A. Generator}

Whereas the electrical networks are formed of DC, the power generation has still relied on conventional and economic AC generators. One of the common primary power sources in the networks is a brushless synchronous generator driven by a diesel engine. The simulation study is conducted with this common source, consisting of a synchronous generator, an IEEE AC5A (a simplified model for brushless excitation systems) [10], and a governor model of a diesel engine provided in [11]. The parameters used for the generator system modeling are provided in Table II.

As variable speed-generation is allowed in marine DC power distribution networks, this function is additionally implemented in the power controller block in Fig. 2. Twodifferent speed levels in the block are assumed to find a higher fault condition: speed reference of 0.83 pu for light load

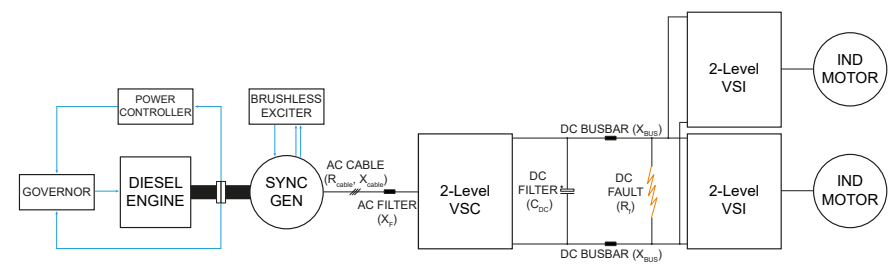

Fig. 2: Schematic diagram of the studied DC power supply systems.

\begin{tabular}{|c|c|c|c|}
\hline \multicolumn{4}{|c|}{ Generator } \\
\hline Parameters & Values & Parameters & Values \\
\hline Capacity & 5 MVA & $R_{a} ; X_{l}$ & $0.0036 \mathrm{pu} ; 0.052 \mathrm{pu}$ \\
\hline Voltage & $480 \mathrm{~V}$ & $X_{d} ; X_{q}$ & $1.56 \mathrm{pu} ; 1.06 \mathrm{pu}$ \\
\hline Power Factor & 0.8 & $X_{d}^{\prime}$ & $0.296 \mathrm{pu}$ \\
\hline Frequency & $60 \mathrm{~Hz}$ & $X_{d}^{\prime \prime} ; X_{q}^{\prime \prime}$ & $0.177 \mathrm{pu} ; 0.177 \mathrm{pu}$ \\
\hline Poles & 6 & $T_{d}^{\prime}$ & $0.37 \mathrm{~s}$ \\
\hline Speed & $1200 \mathrm{rpm}$ & $T_{d}^{\prime \prime} ; T_{q}^{\prime \prime}$ & $0.05 \mathrm{~s} ; 0.05 \mathrm{~s}$ \\
\hline \multicolumn{2}{|c|}{ Exciter } & \multicolumn{2}{|c|}{ Governor } \\
\hline Symbols & Values & symbols & Values \\
\hline$K_{A} ; T_{A}$ & $400 \mathrm{pu} ; 0.02 \mathrm{~s}$ & $K_{P}$ & $12 \mathrm{pu}$ \\
\hline$V_{R M A X} ; V_{R M I N}$ & $7.3 \mathrm{pu} ;-7.3 \mathrm{pu}$ & $T_{1 c} ; T_{2 c}$ & $0.01 \mathrm{~s} ; 0.02 \mathrm{~s}$ \\
\hline$K_{F}$ & $0.03 \mathrm{pu}$ & $T_{3 c}$ & $0.2 \mathrm{~s}$ \\
\hline$T_{F 1} ; T_{F 2} ; T_{F 3}$ & $1.0 \mathrm{~s} ; 0 \mathrm{~s} ; 0 \mathrm{~s}$ & $T_{1 a} ; T_{2 a}$ & $0.25 \mathrm{~s} ; 0.009 \mathrm{~s}$ \\
\hline$K_{E} ; T_{E}$ & $1.0 \mathrm{pu} ; 0.8 \mathrm{~s}$ & $T_{3 a}$ & $0.0384 \mathrm{~s}$ \\
\hline$V_{f d 1} ; V_{f d 2}$ & $5.6 \mathrm{pu} ; 4.2 \mathrm{pu}$ & $T_{M A X} ; T_{M I N}$ & $1.1 \mathrm{pu} ; 0 \mathrm{pu}$ \\
\hline$S_{E}\left[V_{f d 1}\right] ; S_{E}\left[V_{f d 2}\right]$ & $0.86 \mathrm{pu} ; 0.5 \mathrm{pu}$ & $T_{D}$ & $0.024 \mathrm{~s}$ \\
\hline
\end{tabular}

TABLE II: Parameters used for the generator system modeling [10]-[12].

conditions $(<50 \%)$ and speed reference of $1.0 \mathrm{pu}$ for heavy load conditions $(\geq 50 \%)$. Note that the continuous variation of engine speed with regards to load conditions should be necessary for the studies on energy efficiency that is out of the scope of this study.

\section{B. VSC}

For the 2-level VSC, vector current control commonly used for VSCs is implemented in the simulation model (see Fig. 3) [13]. This control scheme is developed in $\mathrm{d}-\mathrm{q}$ frame and involves outer loop and inner loop to independently maintain DC bus voltage of $1 \mathrm{kV}$ and reactive power of 0 MVar.

The overcurrent protection of the VSC is set to $2 \mathrm{pu}$ and can block the IGBTs within a few hundreds of microseconds, considering the switching frequency of $3 \mathrm{kHz}$ in the VSC.

\section{Lines and Filters}

The electrical power generated by the generator is delivered via $\mathrm{AC}$ cables of $50 \mathrm{~m}$ to the VSC. The AC cable is modeled by using the $\pi$ model that consists of lumped resistance,

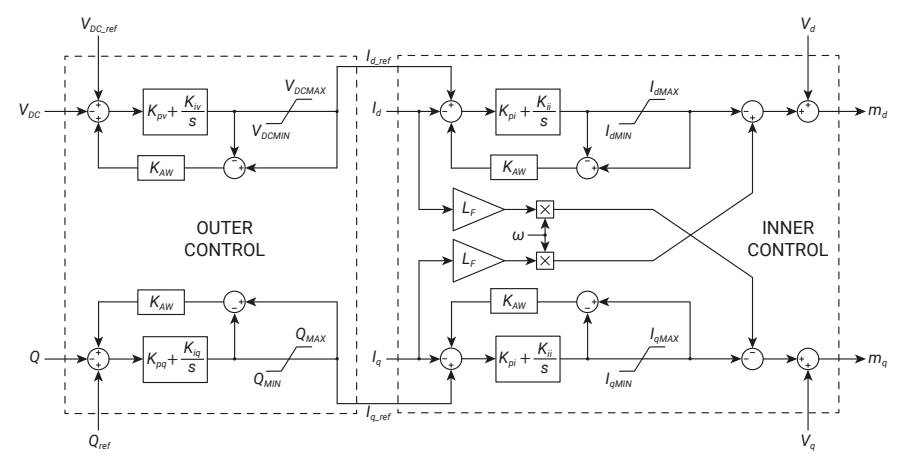

Fig. 3: Block diagram of vector current control. 
lumped inductance, and equally divided capacitance at both ends [9]. Several single core cables in parallel are used to carry the rated current. The parameters of the single core cable with $1 \mathrm{kV}$ and $631 \mathrm{~A}$ are $0.082 \Omega / \mathrm{km}, 0.284 \mathrm{mH} / \mathrm{km}$, and 0.834 $\mu \mathrm{F} / \mathrm{km}[14]$.

The marine DC power distribution networks are based on the centralised configuration [1]. The DC parts are, therefore, assumed to be connected through metallic busbars of $1 \mathrm{~m}$ and their inductance is $1 \mu \mathrm{H} \mathrm{[15].}$

The AC side inductance ( $X_{F}$ in Fig. 2 ) is added in series between the generator and the VSC to reduce the converter through fault current. This inductance is considered as $0.1 \mathrm{pu}$ [16].

The DC-link capacitor $\left(C_{D C}\right.$ in Fig. 2) mitigates a voltage ripple by filtering out harmonic currents. Furthermore, the capacitor decreases harmonic coupling between converters on an instantaneous basis. It can be calculated as a function of the energy to power ratio $\left(E_{S}\right)$ [17]

$$
C_{D C}=\frac{2 S_{C} E_{S}}{V_{D C}^{2}}
$$

where $S_{C}$ is the converter power rating and $E_{S}$ can be chosen to be in the range of $10-50 \mathrm{~kJ} / \mathrm{MW}$. With $S_{C}=4 \mathrm{MW}, E_{S}$ $=10 \mathrm{~kJ} / \mathrm{MW}$, and $V_{D C}=1 \mathrm{kV}, C_{D C}$ is considered as $80 \mathrm{mF}$.

\section{Simulation Model Verification}

Step-load changes are carried out to verify the simulation model implemented: the first step-load change from $0.25 \mathrm{pu}$ to $1.0 \mathrm{pu}$ at $10 \mathrm{~s}$; and the second step-load change from 1.0 put to 0.25 pu at $20 \mathrm{~s}$ (see Fig. 4). When the load draws electrical power of $1 \mathrm{MW}$, the networks can keep the rated voltage of $1 \mathrm{kV}$. The machine speed is also adjusted as $0.83 \mathrm{pu}$ by the variable-speed function implemented in the power controller block.

The step-load change from 0.25 pu to 1.0 pu causes a sudden DC voltage drop and then the voltage is recovered by the voltage regulating function with the time constant of the VSC. The simulation results show that the VSC model has a good
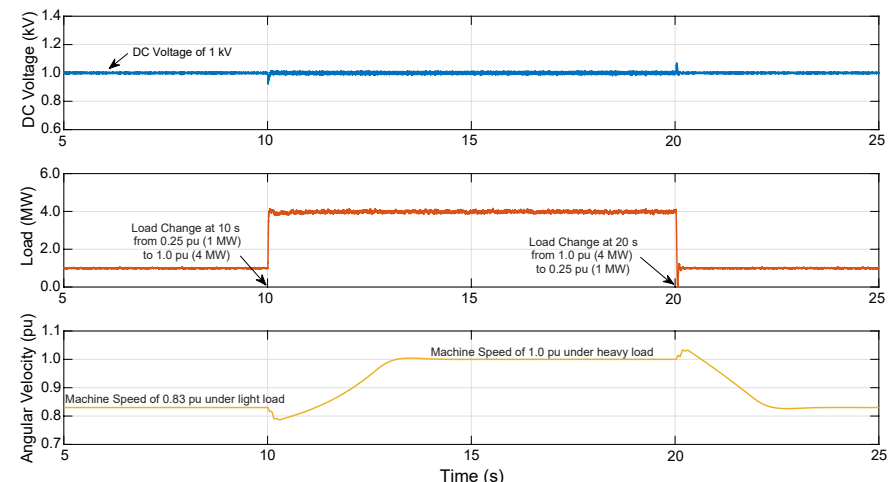

Fig. 4: Simulation model verification by step-load changes: upper - DC voltage, middle - electrical load, and lower generator speed.

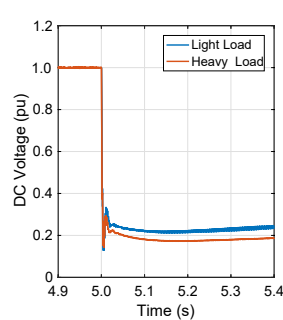

(a)

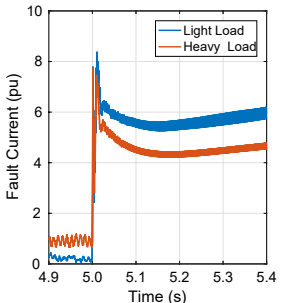

(b)

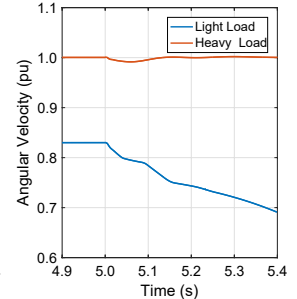

(c)
Fig. 5: Fault characteristics of variable-speed generation systems: (a) DC voltages, (b) DC currents, and (c) generator speeds.

performance in voltage regulation with low voltage drop and fast recovery.

During the step-load increase, the generator speed is decreased for a short time and then the speed approaches its rated value $(1.0 \mathrm{pu})$ that is the target speed for the heavy load. The simulation model also works for the step-load decrease case (see Fig. 4).

\section{Proposed Method Assessment}

Considered study conditions including fault resistance, IGBT ratings, and initial conditions are presented in this section. More importantly, the performance of the proposed method is analysed with regards to the ASC resistance.

\section{A. Study Conditions}

The work of [18] conducted a live DC short-circuit in the marine DC electrical networks and the peak fault current in the work is approximately $50 \mathrm{kA}$. With its nominal voltage of $930 \mathrm{~V}$, the fault resistance $\left(R_{f}\right)$ is a range of $10-20 \mathrm{~m} \Omega$ and thus $10 \mathrm{~m} \Omega$ is considered in this study.

Two high-power IGBT modules of 5SNA 3600E170300 [19] in parallel are considered to handle the rated line voltage

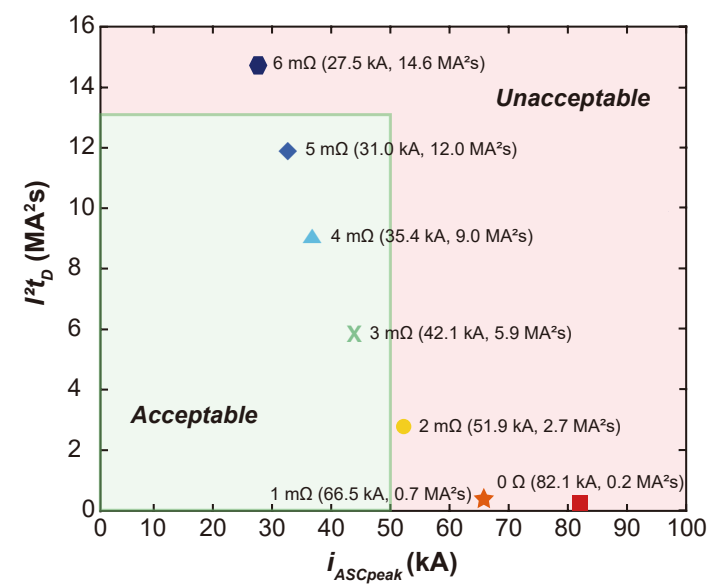

Fig. 6: ASC making currents and through fault energies by the proposed methods with regards to different $R_{A S C}$. 

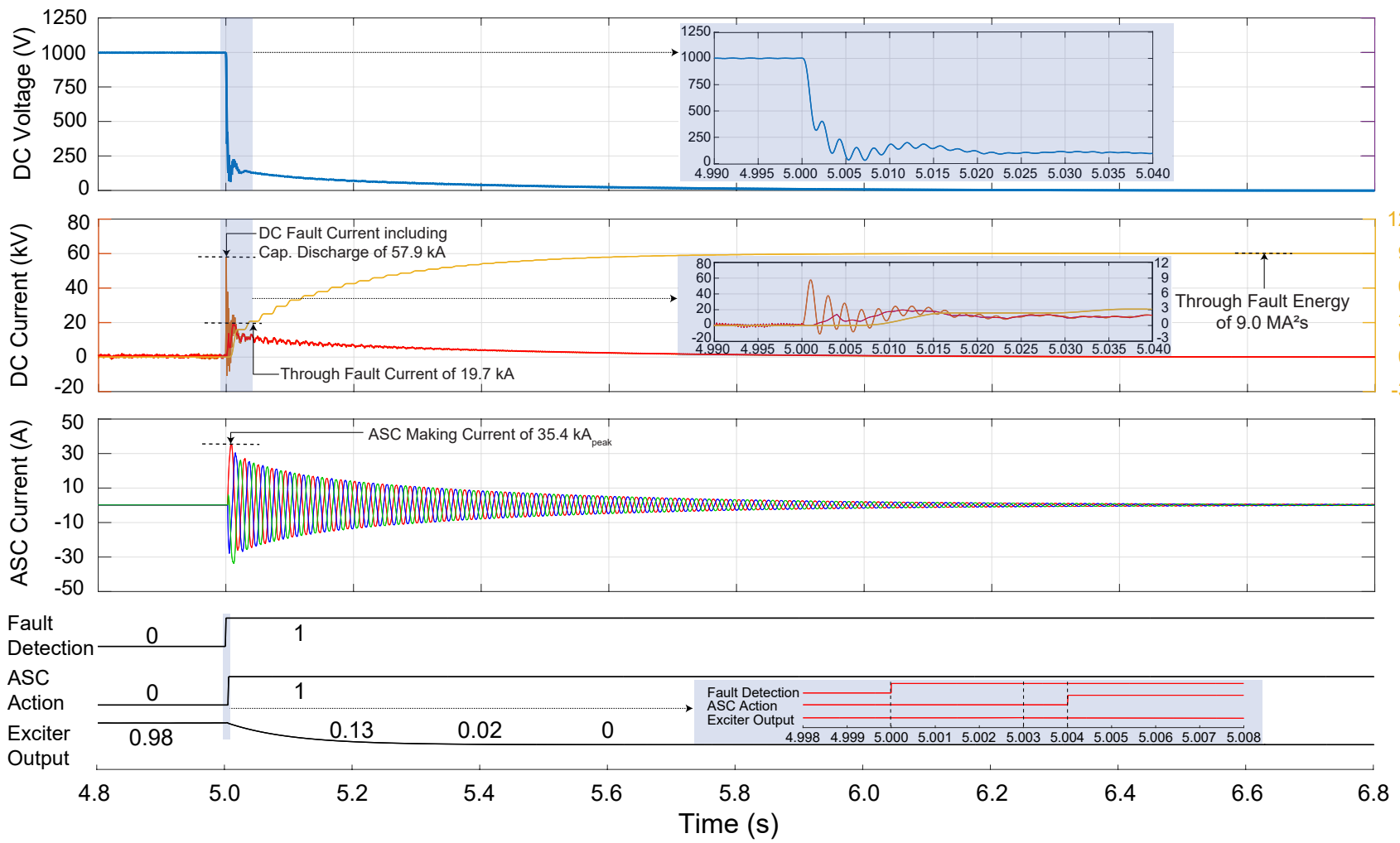

Fig. 7: Transient waveforms for the case of $R_{A S C}=4 \mathrm{~m} \Omega$ : (from the top) the first - DC voltage, the second - DC current (DC fault current including DC-link capacitor current, fault current through the VSC, and the maximum through fault energy among the six IGBT modules), the third - ASC current, and the last - control signals (fault detection, ASC activation, and exciter output).

of $480 \mathrm{~V}$ and the rated DC current of $4 \mathrm{kA}$. With this parallel connection, the modules can be characterised as the rated voltage $\left(V_{C E}\right)$ of $1700 \mathrm{~V}$, the rated current $\left(I_{C}\right)$ of $7200 \mathrm{~A}$, the peak surge current $\left(I_{F S M}\right)$ of $36 \mathrm{kA}$, and the limiting load integral $\left(I^{2} t\right)$ of $12.96 \mathrm{MA}^{2} \mathrm{~s}$.

The VSC is set to detect the overcurrent level of $2 \mathrm{pu}$ (= $8 \mathrm{kA})$. The generator deexcitation and the ASC are activated in $3 \mathrm{~ms}$ [5] and $4 \mathrm{~ms} \mathrm{[6],} \mathrm{[7],} \mathrm{respectively,} \mathrm{after} \mathrm{the} \mathrm{instant} \mathrm{of}$ the fault detection.

A system fault is an unintentional event and can occur under any load conditions. To find higher fault conditions, the fault simulations are conducted under the light load condition (1 MW) and the heavy load condition (4 MW), as shown in Fig. 5. It is observed that the fault current and its energy under the light load are higher than those under the heavy load. This is due to the decreased reactance with the lower machine speed. With this result, the light load condition is considered in the study.

\section{B. Proposed Method Performance}

Aforementioned, the ASC resistance plays an important role to manage the peak making current and the through fault energy. Hence, the performance of the proposed method is analysed with regards to the different ASC resistances: $0 \mathrm{~m} \Omega$,
$1 \mathrm{~m} \Omega, 2 \mathrm{~m} \Omega, 3 \mathrm{~m} \Omega, 4 \mathrm{~m} \Omega, 5 \mathrm{~m} \Omega$, and $6 \mathrm{~m} \Omega$, as shown in Fig. 6. As expected, the lower resistance brings with the higher making current and the lower fault energy. This means that the ASC resistance should carefully be selected to meet the requirements of both (1) and (6).

In detail, the ASC with the zero resistance $\left(R_{A S C}=0\right)$ which is impossible in practice allows for the very low through fault energy of $0.24 \mathrm{MA}^{2} \mathrm{~s}$ (1.9\% of the rating). However, this may cause the making failure as the the making current $(82.1$ $\mathrm{kA}_{\text {peak }}$ ) developed by this impedance is much higher than the making rating of the ASC device $\left(I_{c m}=50 \mathrm{kA}_{\text {peak }}\right)$. In case of the high resistance ASC $\left(R_{A S C}=6 \mathrm{~m} \Omega\right)$, the ASC cannot protect the converter due to its high fault energy $\left(14.6 \mathrm{MA}^{2} \mathrm{~s}\right.$, $113 \%)$, whereas the making current $\left(27.5 \mathrm{kA}_{\text {peak }}, 55 \%\right)$ is controlled much lower than the device rating.

Fig. 6 shows that the three cases of $R_{A S C}=3 \mathrm{~m} \Omega, 4 \mathrm{~m} \Omega$, and $5 \mathrm{~m} \Omega$ enable to successfully govern both the current and the energy with the fulfilment of the requirements. Among the three cases, the case of $R_{A S C}=4 \mathrm{~m} \Omega$ which has enough margins in the making current and the limiting load integral is presented in Fig. 7 with its transient characteristics and the fault control actions.

For the fault at $5 \mathrm{~s}$, the VSC controller promptly detects it by measuring the DC link discharge current. The controller 
stops the IGBTs switching and activates the deexcitation and the ASC in $3 \mathrm{~ms}$ and $4 \mathrm{~ms}$, respectively.

The making current of the case of $R_{A S C}=4 \mathrm{~m} \Omega$ is observed as $35.4 \mathrm{kA}_{\text {peak }}(70.8 \%)$. The peak through fault current is decreased from its original peak value of 8.4 pu (33.6 kA) in Fig. $5 \mathrm{~b}$ to $4.9 \mathrm{pu}(19.7 \mathrm{kA}, 54.7 \%)$ in Fig. 7 which is much lower than its rating $(36 \mathrm{kA})$. Moreover, the fault current gradually diminishes in time by the continuous decrease in the exciter output and finally becomes zero. The result also verifies that the propose method can manage the through fault energy $\left(9.0 \mathrm{MA}^{2} \mathrm{~s}, 69.4 \%\right)$ by the mitigated and diminished fault current within the IGBT module rating (12.96 $\left.\mathrm{MA}^{2} \mathrm{~s}\right)$.

\section{Conclusion}

This paper has proposed the new breakerless protection method for the VSC-based marine DC power supply systems. The proposed method is based on the ASC method on AC side to mitigate the through fault current and its energy, and the generator deexcitation to eliminate the fault current supplied by the generator.

The simulation study verifies the performance of the propose method and also provides important information on the proposed method. The ASC resistance should carefully be selected to achieve the safe making operation of the ASC as well as to manage the through fault energy. Fast ASC action allows for noticeably mitigating the amplitude of the peak through fault current.

The method can be implemented with commercially available technologies and additionally requires the only ASC device in the circuit. In other words, the method is technically reasonable and economic. Hence, it could be considered as an alternate protection way for the VSC-based marine DC power supply systems.

\section{APPENDIX}

The parameters for $Y(t)$ and $F(t)$ in (4) are

$$
\begin{aligned}
& Y(t)=\left(\frac{1}{2 Z_{S}^{\prime \prime}+2 Z_{A S C} / / 2 Z_{D C}}-\frac{1}{2 Z_{S}^{\prime}+2 Z_{A S C} / / 2 Z_{D C}}\right) e^{-\frac{t}{T_{d}^{\prime \prime}}} \\
&+\left(\frac{1}{2 Z_{S}^{\prime}+2 Z_{A S C} / / 2 Z_{D C}}-\frac{1}{2 Z_{S}+2 Z_{A S C} / / 2 Z_{D C}}\right) e^{-\frac{t}{T_{d}^{\prime}}} \\
&+\frac{1}{2 Z_{S}+2 Z_{A S C} / / 2 Z_{D C}}, \\
& Z_{S}^{\prime}= \sqrt{\left(R_{a}+R_{\text {cable }}\right)^{2}+\left(X_{d}^{\prime}+X_{\text {cable }}\right)^{2}}, \\
& Z_{S}= \sqrt{\left(R_{a}+R_{\text {cable }}\right)^{2}+\left(X_{d}+X_{\text {cable }}\right)^{2}}, \\
& F(t)=1-u\left(t-t_{d}\right)+u\left(t-t_{d}\right) \frac{T_{d}^{\prime} e^{-\left(t-t_{d}\right) / T_{d}^{\prime}-T_{e} e^{-\left(t-t_{d}\right) / T_{e}}}}{T_{d}^{\prime}-T_{e}}
\end{aligned}
$$

where
$X_{d}^{\prime} \quad$ is the direct axis transient reactance,

$X_{d} \quad$ is the direct axis synchronous reactance,

$T_{d}^{\prime \prime} \quad$ is the direct axis subtransient time constant,

$T_{d}^{\prime} \quad$ is the direct axis transient time constant,

$t_{d} \quad$ is the time delay to activate the deexcitation after the fault instant, and

$T_{e} \quad$ is the exciter time constant.

\section{REFERENCES}

[1] S. Kim, G. Ulissi, S.-N. Kim, and D. Dujic, "Protection Coordination for Reliable Marine DC Power Distribution Networks," IEEE Access, vol. 8, pp. 222813-222823, 2020.

[2] "High Efficiency Integrated Compact Power System for Electric Propulsion Vessels," [online], Dec. 2019. Available: https://www.ingeteam.com

[3] "Mastering DC Distribution for Ultimate Marine Drive Efficiency," [online], Mar. 2020. Available: https://theswitch.com/marine/.

[4] S. Kim, D. Dujic and S. Kim, "Protection Schemes in Low-Voltage DC Shipboard Power Systems," in PCIM Europe 2018; International Exhibition and Conference for Power Electronics, Intelligent Motion, Renewable Energy and Energy Management, 2018, pp. 1-7.

[5] S. Settemsdal, E. Haugan, K. Aagesen, and B. Zahedi, "New enhanced safety power plant solution for DP vessels operated in closed ring configuration", in Proc. Dyn. Positioning Conf., pp. 1-21, 2014.

[6] D. Gentsch, T. Fugel and G. Salge, "New Ultra Fast Earthing Switch (UFES) device based on the vacuum switching principle," in $24^{\text {th }}$ ISDEIV 2010, 2010, pp. 121-124.

[7] Y. Jeong, H. Lee, S. Lee, K. Ahn, and Y. Kim, "Reliable arc flash damage mitigating system in MV switchgear," in $25^{\text {th }}$ international conference and exhibition on electricity distribution (CIRED 2019), 2019, pp. 1-5.

[8] S. Kim, S.-N. Kim and D. Dujic, "Impact of Synchronous Generator Deexcitation Dynamics on the Protection in Marine DC Power Distribution Networks," IEEE Transactions on Transportation Electrification, vol. 7, no. 1, pp. 267-275, 2021.

[9] H. Saadat, Power System Analysis. Boston: McGraw-Hill, 2004

[10] "IEEE Recommended Practice for Excitation System Models for Power System Stability Studies," IEEE Std 421.5-2005 (Revision of IEEE Std 421.5-1992), pp.1-93, 21 April 2006.

[11] J. Alsaihati, "Simulation and economic analysis of a hybrid wind diesel system for remote area power supply," MSc thesis, Dept. Elect. Eng., National Sun Yat-Sen Univ., 2010.

[12] S. Kim, "Protection coordination in marine DC power distribution networks," PhD thesis, Dept. Elect. Eng., École Polytechnique Fédérale de Lausanne (EPFL), 2020.

[13] M. A. Hannan et al., "Advanced Control Strategies of VSC Based HVDC Transmission System: Issues and Potential Recommendations," IEEE Access, vol. 6, pp. 78352-78369, 2018.

[14] TMC, Cheonan, Republic of Korea. Marine \& Shipboard Cable (2010). Accessed: May 4, 2021. [Online]. Available: https://www.powerandcables.com

[15] "IEEE Guide for the Application of Shunt Reactor Switching," IEEE Std C37.015-2009 (Revision of IEEE Std C37.015-1993), vol., no., pp.1-70, 12 Feb. 2010.

[16] U. Javaid, F. D. Freijedo, D. Dujic and W. van der Merwe, "Dynamic Assessment of Source-Load Interactions in Marine MVDC Distribution," IEEE Transactions on Industrial Electronics, vol. 64, no. 6, pp. 4372-4381, June 2017.

[17] D. Jovcic and K. Ahmed, High Voltage Direct Current Transmission: Converters Systems and DC Grids. Hoboken, NJ, USA:Wiley, 2015.

[18] S. Settemsdal, L. Barstad, and K. Tjong, "Fault Ride-Through Testing of LV Power Solution BlueDrivePlusC", in Proc. Dyn. Positioning Conf., 2016, pp. 1-15.

[19] ABB, Lenzburg, Switzerland. HiPak IGBT Module - 5SNA $3600 E 170300$ (2014). Accessed: May 4, 2021. [Online]. Available: https://search.abb.com 